DOI: http://dx.doi.org/10.21686/2073-1051-2020-1-99-112

\title{
Евгений БУХВАЛЬД
}

\section{НАЦИОНАЛЬНАЯ БЕЗОПАСНОСТЬ РОССИИ: СТАРЫЙ ЗАКОН И НОВЫЕ ПРОБЛЕМЫ}

\begin{abstract}
В ближайшее время предстоит обновление такого важного документа стратегического планирования, как Стратегия национальной безопасности Российской Федерации. Это связано с тем, что действующая Стратегия национальной безопасности была принята в 2015 г., а, в соответствии с Федеральным законом «О стратегическом планировании в Российской Федерации», обновление данной Стратегии должно производиться не реже, чем раз в 6 лет. Однако в нынешней ситуаиии подготовка новой Стратегии национальной безопасности - это не просто некое обновление уже имеющегося документа. По существу, речь идет о задаче системного характера, в ходе которой предстоит добиться органичного включения данной Стратегии в единую «вертикаль» документов стратегического планирования. Предстоит также утвердить роль Стратегии как одного из ключевых источников иелеполагания в практике стратегического планирования $и$, конечно, закрепить в ней те риски и угрозы национальной безопасности, в т.ч. экономического характера, которые сложились в последнее время. Кроме того, предполагается существенное обновление Федерального закона «О безопасности», который должен закрепить современную систему стратегий безопасности, их роль в формировании приоритетов стратегического планирования, а также в закреплении экономикоправовых основ федеративных отнотений в стране.
\end{abstract}

Ключевые слова: национальная безопасность, экономическая безопасность, риски и угрозы, стратегическое планирование, целеполагание, правовое регулирование

JEL: H560, R58

Принятие Федерального закона «О стратегическом планировании в Российской Федерации» ${ }^{1}$ не только в значительной мере «реабилитировало» саму идею планирования как необходимого инструмента управления социально-экономическими процессами в современных условиях и не только подчеркнуло важность стратегического, долгосрочного характера экономической политики государства. Принятие данного закона особо акцентировало внимание на требованиях на-

1 Федеральный закон от 28 июня 2014 г. № 172-Ф3 «О стратегическом планировании в Российской Федерации» // КонсультантПлюс. URL: http://www.consultant.ru/document/ cons_doc_LAW_164841/ 
циональной безопасности как одного из главных факторов целеполагания в стратегировании социально-экономического развития страны и ее регионов. Даже самый простой анализ текста ФЗ № 172 показывает, что термин «безопасность» употребляется в нем едва ли не реже, чем само «стратегическое планирование». Согласно закону, Стратегия национальной безопасности ${ }^{2}$ не только относится к числу важнейших документов стратегического планирования, но и выступает базой для подготовки иных подобных документов, в частности Стратегии пространственного развития Российской Федерации ${ }^{3}$.

Однако многочисленные указания в ФЗ № 172 на «особую роль» Стратегии национальной безопасности в системе стратегического планирования и в подготовке обеспечивающих ее документов выглядят достаточно формально и не подкрепляются конкретными механизмами реализации этой роли в практике управления. В частности, в Стратегии пространственного развития указано, что этот документ «учитывает основные положения Стратегии национальной безопасности Российской Федерации». Однако, что это за положения и как именно они учтены в данной стратегии, никоим образом не конкретизируется. Да и как этот «учет» возможен в принципе, принимая во внимание, что все положения Стратегии изложены весьма декларативно. В результате в настоящее время складывается необходимость практически заново сформулировать и реализовать роль фактора национальной безопасности в практике стратегического планирования, в т.ч. и в «вертикали» этой системы управления сообразно условиям России как государства федеративного типа, а затем и законодательно закрепить это взаимодействие.

\section{Закон и Стратегия - что в первую очередь?}

В практике государственного управления часто складывается ситуация, когда при необходимости реформ в той или иной сфере социально-экономических отношений возникает дилемма: что целесообразно сделать в первую очередь - подготовить концептуальное обоснование сути и задач намечаемых преобразований или сформировать для них нормативно-правовую основу. Несоблюдение этой последовательности в каждом конкретном случае создает опасность затягивания реформ и существенного «сжатия» их позитивного эффекта. Примером может служить ситуация с принятием в 2003 г. Федерального закона «Об общих принципах организации местного самоуправления...» ${ }^{4}$. Особенность этого закона состояла в том, что он не просто корректировал некоторые правовые нормы в сфере своего регулирования. По существу, закон

2 Указ Президента Российской Федерации от 31 декабря 2015 г. № 683 «О Стратегии национальной безопасности Российской Федерации» // КонсультантПлюс. URL: http:// www.consultant.ru/document/cons_doc_LAW_191669/

${ }^{3}$ Распоряжение Правительства РФ от 13 февраля 2019 г. № 207-р «Об утверждении Стратегии пространственного развития до 2025 года» // Официальный сайт Правительства России. URL: http://government.ru/docs/35733/

4 Федеральный закон от 6 октября 2003 г. № 131-Ф3 «Об общих принципах организации местного самоуправления в Российской Федерации» // КонсультантПлюс. URL: http://www.consultant.ru/document/cons_doc_LAW_44571/ 
предлагал стране совершенно иную модель местного самоуправления по сравнению с той, что действовала на момент принятия закона.

В связи с этим в процессе обсуждения данного закона на стадии законопроекта эксперты предлагали предварительно или по крайней мере параллельно подготовить для него концептуальную основу. Действовавшие на тот момент «Основные положения государственной политики в области развития местного самоуправления в Российской Федерации» ${ }^{5}$ не отличались достаточной конкретностью и не могли служить «рабочей программой» при переходе к новой организации самоуправления в стране. Однако эти призывы не были услышаны, и закон был принят вне концептуальной базы для обоснования и конкретизации его основных положений. В результате это привело к многочисленным трудностям в реализации муниципальной реформы; за прошедший период Ф3 № 131 подвергся бесчисленному количеству изменений и дополнений, а многие исходные положения реформы вообще оказались повернутыми вспять.

Во многом аналогичная ситуация складывается ныне и с федеральным законом о стратегическом планировании. Закон утверждал собой принципиально новое понимание роли планирования в развитии российской экономики, радикально отличавшееся от ранее доминировавших либеральных доктрин рыночного хозяйства. Правда, и в этом случае закон изначально содержал себе некие коллизии. Так, название закона говорит о стратегическом планировании в целом, а текст закона регулирует деятельность только публично-правовых субъектов такого планирования. Этот контекст очень важен, т.к. проблематика национальной безопасности в равной мере включает в себя вопросы безопасного функционирования не только публично-правовых образований разного уровня, но и безопасности бизнеса и даже отдельных граждан. Кроме того, многие эксперты утверждали, что закон представляет собой крышу, под которой нет дома. Другими словами, закон пытается установить практику стратегического планирования в той ситуации, когда нет ни концептуальных документов, ни нормативно-правовой базы, в целом определяющих роль плановых начал в развитии российской экономики.

Однако бывают примеры и другого свойства. Длительное время в Государственной Думе РФ находился на рассмотрении проект федерального закона об основах государственной политики регионального развития ${ }^{6}$ В итоге законопроект не получил поддержки и был окончательно снят с обсуждения. Но в 2017 г., в разгар работы над Стратегией пространственного развития был принят Указ Президента РФ по ос-

5 Указ Президента РФ от 15 октября 1999 г. № 1370 «Об утверждении Основных положений государственной политики в области развития местного самоуправления в Российской Федерации» // КонсультантПлюс. URL: http://www.consultant.ru/document/ cons_doc_LAW_24661/

6 Законопроект № 18259-3 «Об основах государственного регулирования регионального развития в Российской Федерации» // официальный сайт Государственной Думы РФ. URL: http://asozd2.duma.gov.ru/main.nsf/\%28SpravkaNew\%29? OpenAgent\&RN=18259-3\&02 (B настоящее время законопроект снят с обсуждения и находится в архиве). 
новам государственной политики регионального развития 7 . Здесь возникла «обратная ситуация». Концептуальный документ в отношении государственной политики регионального развития имеется, а его законодательное обеспечение так и не было сформировано. Ф3 № 172 по стратегическому планированию этой задачи в полной мере не решает, а Стратегия пространственного развития - документ, опять-таки, программно-концептуального, а не законодательного уровня. Можно предположить, что именно отсутствие адекватной законодательной базы привело к тому, что положения Основ государственной политики регионального развития в итоге были отражены в Стратегии пространственного развития лишь частично, да и сам документ оценивается экспертным сообществом как достаточно малоконкретный в плане обоснования тех или иных практических действий [1].

Формирование правовой базы национальной безопасности Российской Федерации началось с принятия 5 марта 1992 г. Закона Российской Федерации «О безопасности» ${ }^{8}$ (утратил силу 28 декабря 2010 г.). Закон в целом обеспечивал системный подход к задачам обеспечения национальной безопасности, определял категориальный аппарат этого вектора государственной политики. Закон исходил из логики формирования национальной безопасности в последовательности приоритетов «личность - общество - государство», что соответствует нормам современного демократического государства. Уже на данном этапе возникла тенденция к обособлению проблематики экономической безопасности страны. Эта задача была решена Указом Президента РФ от 29 апреля 1996 г. № 608 «О государственной стратегии экономической безопасности Российской Федерации (Основных положениях) ${ }^{9}$ ». Вслед за этим Указом последовало соответствующее постановление Правительства Р $\Phi^{10}$.

Как важный этап формирования правовых основ политики национальной безопасности следует также отметить такой документ, как «Концепция национальной безопасности Российской Федерации», утвержденная Указом Президента Российской Федерации от 17 декабря 1997 г. № 1300. В этом документе национальная безопасность определялась как безопасность многонационального народа Российской Федерации - носителя суверенитета и единственного источника вла-

7 Указ Президента РФ от 16 января 2017 г. № 13 «Об утверждении Основ государственной политики регионального развития Российской Федерации на период до 2025 г.» // КонсультантПлюс. URL: http://www.consultant.ru/document/cons_doc_LAW_210967/ f938e46a4000bf25f99c70c69823278591395d7d/

8 Закон Российской Федерации от 5 марта 1992 г. № 2446-1 «О безопасности» // КонсультантПлюс. URL: http://www.consultant.ru/cons/cgi/online.cgi?base=LAW\&dst=\&n= $376 \&$ req $=$ doc $\# 024577889521404$

9 Указ Президента РФ от 29 апреля 1996 г. № 608 «О государственной стратегии экономической безопасности Российской Федерации (Основных положениях)» // КонсультантПлюс. URL: http://www.consultant.ru/cons/cgi/online.cgi?base=LAW;n=92725; req $=\mathrm{doc} \# 0010251515677900391$ (документ утратил силу).

10 Постановление Правительства РФ от 27 декабря 1996 г. № 1569 «О первоочередных мерах по реализации Государственной стратегии экономической безопасности Российской Федерации (Основных положений), одобренной Указом Президента Российской Федерации от 29 апреля 1996 г. № 608» // КонсультантПлюс. URL: http://www.consultant. ru/cons/cgi/online.cgi?base $=\mathrm{EXP} ; \mathrm{n}=242732 ;$ req $=$ doc $\# 09882013108708074$ 
сти. Такое определение соответствовало нормам ст. 3 принятой в 1993 г. Конституции Российской Федерации [2].

В настоящее время стратегический блок по вопросам безопасности страны представлен значительным числом различных документов (стратегий, доктрин и даже законов). В нашем исследовании мы коснемся лишь двух из них: уже названной Стратегии национальной безопасности и появившейся позднее Стратегии экономической безопасности ${ }^{11}$. Статус этих двух близких по характеру документов весьма различен. Стратегия национальной безопасности упоминается в соответствующем Федеральном законе «О безопасности» ${ }^{12}$ и в Федеральном законе «О стратегическом планировании...». Напротив, Стратегия экономической безопасности в этих законах не представлена, что делает ее позиции в системе документов стратегического планирования достаточно неопределенными [3].

Между тем для целей стратегирования социально-экономического развития Стратегия экономической безопасности более представительна, чем «экономический блок» Стратегии национальной безопасности (по некоторым вопросам социально-экономического свойства между двумя документами есть расхождения, но они малосущественны). Несомненно, что Стратегия экономической безопасности содержит более широкий круг вопросов, которые формально должны были бы подлежать обязательному учету при разработке документов стратегического планирования. Кроме того, в этом документе более подробно представлены целевые «выходы» требований безопасности, хотя опять-таки вне конкретной количественной определенности. Во всяком случае в официальных версиях этих двух стратегий, которые содержатся в базах правовой информации, никаких количественно выраженных целевых индикаторов нет, а комментарии типа «такие индикаторы в принципе есть, но показать их нельзя» трудно воспринимать как норму государственного управления.

В Стратегии национальной безопасности содержится всего 10 показателей для «оценки состояния национальной безопасности», из которых 8 так или иначе могут быть отнесены к сфере социально-экономического развития. В Стратегии экономической безопасности таких показателей значительно больше - 40 и практически все из них, кроме небольшого исключения (например, уровня преступности и пр.), могут рассматриваться как индикаторы социально-экономического характера. Однако и в том, и в другом случае эти показатели очень пассивны; из них трудно заключить, что конкретно они значат для национальной, в т.Ч. для экономической, безопасности страны. Например, в обоих документах представлен такой показатель, как «децильный коэффициент (соотношение доходов 10 процентов наиболее обеспеченного населения и 10 процентов наименее обеспеченного населения»). Показатель значи-

11 Указ Президента Российской Федерации от 13 мая 2017 г. № 208 «О Стратегии экономической безопасности Российской Федерации на период до 2030 года» // Гарант.py. URL: http:// www.garant.ru/products/ipo/prime/doc/71572608/

12 Федеральный закон от 28 декабря 2010 г. № 390-Ф3 «О безопасности»// КонсультантПлюс. URL: http://www.consultant.ru/document/cons_doc_LAW_108546/ 
мый, но какое конкретное отношение он имеет к проблеме национальной безопасности? В Стратегии экономической безопасности есть такие показатели, по отношению к которым трудно сказать, с каким знаком (плюс или минус) их следует рассматривать в контексте требований безопасности. Это, например, показатели «индекс производства по виду экономической деятельности «добыча полезных ископаемых»; «оборот розничной торговли» и пр.

Показатели «оценки состояния» безопасности в документе не систематизированы (например, как макроэкономические, финансово-бюджетные, социальные и пр.). Так, показатель «дефицит федерального бюджета» указан на позиции 20, а «дефицит консолидированного бюджета субъектов Федерации» - на позиции 32. Показатель «доля граждан с денежными доходами ниже величины прожиточного минимума» указан на позиции 27, а близкий по содержанию показатель «доля работников с заработной платой ниже величины прожиточного минимума трудоспособного населения» - на позиции 39.

По отношению к Стратегии экономической безопасности четко просматривается отсутствие $100 \%$-ной корреспонденции между основными положениями документа и его целевыми индикаторами. Получается так, что многим важным положениям (требованиям) Стратегии не соответствуют какие-либо целевые индикаторы, а некоторым целевым индикаторам не соответствуют те или иные положения документа и вытекающие из них требования безопасности. Все это крайне затрудняет использование документов по безопасности как одну из основ целеполагания для всей практики стратегического планирования.

Разумеется, в настоящее время в существенном обновлении нуждаются оба документа по безопасности Российской Федерации, включая и решение обсуждаемого в последнее время вопроса о целесообразности Стратегии экономической безопасности как отдельного документа или полной интеграции ее основных положений в обновленный вариант Стратегии национальной безопасности [4]. Аргументом в пользу единого документа является отмечаемая многими экспертами взаимосвязь экономических и внеэкономических (например, внешнеполитических) факторов безопасности. Это проявляет себя в том, что «внешние» факторы (например, санкционные режимы) оказывают заметное влияние на темпы и структуру российской экономики. С другой стороны, чем более активно работают внутренние предпосылки устойчивого социально-экономического развития страны, тем выше ее шансы противостоять разного рода санкционным и прочим подобным угрозам и даже свести их влияние к минимуму [5]. Однако есть и аргументы в пользу Стратегии экономической безопасности как самостоятельного документа. Они касаются того, что требования в области экономической безопасности более подвижны, могут задаваться в сценарном варианте и, следовательно, вправе рассчитывать на самостоятельную документальную платформу. Четкую, ясную позицию по данному вопросу предстоит сформировать при обновлении Федерального закона «О безопасности». 


\section{Конкретность как условие действенного целеполагания}

Системный характер воздействия требований безопасности на практику стратегического планирования во многом предполагает системность тех изменений и дополнений, которые ныне востребованы в законодательстве о безопасности. Прежде всего, полагаем мы, необходимо уточнить в законе объект его регулирующего воздействия. В настоящее время в законе по этому вопросу четкой определенности нет. Имеется в виду допускаемая в нем аналогия понятий «безопасность» и «национальная безопасность», которые, как отмечено в документе, включают в себя безопасность государства, общественную безопасность, экологическую безопасность, безопасность личности и иные виды безопасности (ст. 1). Как и многие эксперты [6], мы полагаем, что такая аналогия с понятием безопасности и его подобная структуризация неправомерны. Сам по себе термин «безопасность» носит общий характер и едва ли годится как объект для законодательного регулирования. Федеральный закон, по нашему мнению, должен опираться на понятие «национальная безопасность» и давать его структуризацию следующим образом: безопасность государства, выключая все макроэкономические аспекты этой безопасности; безопасность предпринимательства; безопасность гражданского общества и личности. Соответственно, безопасность государства должна включать в себя ее военно-политические, экономические, экологические аспекты; вопросы промышленной, энергетической, транспортной и продовольственной безопасности страны. Такой подход, на наш взгляд, не отрицает целесообразности подготовки Стратегии экономической безопасности как особого документа, статус которого в этом случае должен быть закреплен также и в ФЗ № 172 о стратегическом планировании ввиду ее особой важности для процесса социально-экономического стратегирования.

Последовательное уточнение объекта регулирования в Ф3 № 390 закономерно инициирует необходимость включения в закон развернутого глоссария с определением основных используемых в нем понятий. В настоящее время достаточно подробный глоссарий представлен в Стратегии экономической безопасности. Однако он, очевидно, не исчерпывает всего круга понятий национальной безопасности, да и в целом было бы убедительнее включить глоссарий в документ законодательного уровня, как это сделано в ФЗ № 172 о стратегическом планировании. Как мы полагаем, в этом разделе закона № 390 должны быть зафиксированы ключевые понятия, входящие в сферу его регулирования, а именно национальная безопасность, безопасность государства, экономическая безопасность, личная безопасность граждан и пр.

Особое внимание при этом следует обратить на ключевую в проблематике безопасности и управления ею триаду понятий: «вызовы - puски - угрозы», которыми по традиции насыщены - и не всегда в четкой логической увязке! - все работы и документы по этой теме. Наверное, здесь можно предложить следующую логическую цепь: вызовы создают угрозы; угрозы генерируют риски; риски становятся объектом целенаправленного управления. Однако закон должен не только содержать 
четкие определения этих понятий, но и категорически требовать, чтобы положения всех стратегий и иных документов по безопасности соответствовали этим определениям, причем в достаточной мере конкретности. Пока это требование, в частности в Стратегии экономической безопасности, в полной мере не реализуется, что также осложняет практическое использование этих документов как одной из основ в формировании всей системы документов стратегического планирования.

Возьмем для примера раздел II данного документа, который назван «Вызовы и угрозы экономической безопасности». Здесь представлено 25 позиций, относящихся к самым различным сферам экономики, социальной сферы, финансов, экологии. Понять из этого списка, что относится к «вызовам», а что - к «угрозам», невозможно. Да и сами формулировки, приведенные в этом разделе, внушают определенные сомнения. Так, в документе имеется позиция (№ 24) «неравномерность пространственного развития Российской Федерации, усиление дифференциации регионов и муниципальных образований по уровню и темпам социально-экономического развития». Сразу возникает вопрос: подобная неравномерность - это вызов или уже реальная угроза? Скорее всего, ни то, ни другое. Указанная неравномерность и связанная с ней межрегиональная дифференциация - это, действительно, весьма негативный тренд пространственного развития экономики, который при определенных условиях может создавать риски для безопасности страны. Но при каких именно условиях и какие именно риски здесь возможны - об этом можно только догадываться.

Но есть вопросы и по деталям данной в Стратегии формулировки. Например: неравномерность пространственного развития Российской Федерации и усиление дифференциации регионов и муниципальных образований - это одно и то же или нечто разное? Не ясно, почему в Стратегии «усиление дифференциации» декларируется как очевидный факт и как источник угроз, хотя на деле этого сейчас не происходит [7]. А если не происходит, то является ли угрозой уже сложившийся уровень такой межрегиональной дифференциации или нет? Фактически, такую критическую «разборку» можно провести по многим позициям Стратегии экономической безопасности. Например, «несбалансированность национальной бюджетной системы» (при нынешнем значительном профиците федерального бюджета!); «усиление дифференциации населения по уровню доходов» (но это еще надо доказать и объяснить, какие именно угрозы и риски с этим связаны) и пр. Собственно, все это лишь интерпретирует соответствующие положения, данные в ранее принятой Стратегии национальной безопасности, а именно «усиление дифференциации населения по уровню доходов» (п. 51); «несбалансированность национальной бюджетной системы»; «неравномерное развитие регионов» (п. 56) и пр.

Как уже было отмечено выше, даже немногие содержащиеся в стратегических документах по безопасности целевые индикаторы («пороговые значения») приведены без количественной размерности, хотя оба документа предусматривают такую процедуру, как проведение мониторинга реализации этих стратегий. В научной литературе по проблематике 
национальной безопасности дискутируется вопрос о том, являются ли целевые индикаторы стратегических документов аналогом «пороговых значений» безопасности по тем или иным ее составляющим. По нашему мнению, полная аналогия здесь неуместна. «Пороговые значения» фиксируют тот рубеж, при котором негативное развитие тех или иных социально-экономических тенденций перерастает в угрозу безопасности с четко сформулированной системой рисков или, напротив, тот рубеж, когда позитивное развитие тех или иных социально-экономических процессов приводит к тому, что ранее возникшая угроза как бы «снимается». При этом период возможного «позитивного» продвижения ситуации к пороговому значению безопасности (например, по сокращению экономической дифференциации российских регионов) может быть достаточно значительным. Учитывая, что стратегии периодически обновляются, в этих документах по соответствующему параметру может указываться как «пороговое значение», так и тот целевой показатель приближения к нему, который предполагается достичь в пределах действия данного стратегического документа.

Четко зафиксированные пороговые значения и целевые индикаторы - необходимая аналитическая нормативная база, без которой невозможно эффективное функционирование всей системы стратегического планирования во всех ее компонентах. Это касается не только государственных программ, но и национальных проектов, социально-экономических и бюджетных прогнозов, обоснований к проектам федерального бюджета и пр. Напротив, отсутствие в действующих стратегиях безопасности как «пороговых значений», так и целевых индикаторов превращает эти документы в тексты чисто познавательного характера, а их практическую значимость как основы для разработки и реализации иных документов стратегического планирования со всей очевидностью сводит к минимуму.

Однако для превращения Стратегий безопасности в реально работающий документ стратегического планирования недостаточно лишь добиться отражения в них численных значений целевых индикаторов и/или пороговых значений. Необходимо разработать и закрепить в законе экономический и институциональный механизмы реализации этих значений. Действующая версия Ф3 № 390 четкого ответа на этот вопрос не содержит. В соответствии с п. 2 ст. 10 данного закона, Правительство РФ «формирует федеральные целевые программы в области обеспечения безопасности и обеспечивает их реализацию». Однако о каких программах идет речь, остается неясным. При этом закон также не определяет того, должны ли эти программы охватывать собой все требования (целевые значения), изложенные в стратегиях национальной, в т.ч. экономической, безопасности, или только некоторые из них.

По политическим, в частности военно-политическим, составляющим национальной безопасности подобный механизм более чем очевиден. Так, в настоящее время в системе государственных программ Российской Федерации содержится блок «Обеспечение национальной безопасности», в рамках которого действуют две государ- 
ственные программы: «Обеспечение обороноспособности страны» и «Обеспечение государственной безопасности». Все остальные государственные программы (порядка 40) составляют еще четыре блока, а именно: «Новое качество жизни», «Инновационное развитие и модернизация экономики», «Сбалансированное региональное развитие» и «Эффективное государство». Это дает возможность предположить два возможных варианта программной реализации требований стратегических документов по национальной безопасности.

Один вариант предполагает разработку и реализацию целевых государственных программ, ориентированных именно на достижение требований национальной, в т.ч. экономической, безопасности страны. Однако на деле такой вариант едва ли реализуем. Этой связано с тем, что содержание стратегий безопасности, в частности по их социально-экономическим компонентам, очень широко. Реализуя этот вариант, по сути пришлось бы продублировать всю систему уже действующих программ в разрезе четырех названных блоков этих документов.

Второй вариант, который представляется вполне реализуемым в практике управления, основывается на имплементации проблематики безопасности в иные документы стратегического планирования. Речь идет о законодательном установлении требований к действующим государственным программам и, возможно, национальным проектам относительно обязательного включения в эти документы стратегического планирования блока «Реализация требования национальной безопасности Российской Федерации», в т.ч. в систему ожидаемых результатов (индикаторов) выполнения данных программ и проектов для оценки степени их реализации. При этом должно быть законодательно зафиксировано положение о том, что, если тому или иному требованию национальной безопасности не соответствует какая-либо государственная программа или ее составляющая часть (целевая программа), национальный (федеральный) проект и пр., то разработка документа стратегического планирования, реализующего соответствующее требование стратегии безопасности, должна быть признана обязательной.

Примером может служить зафиксированное в обеих действующих стратегиях безопасности требование сокращения межрегиональной экономической дифференциации. Однако какие именно документы стратегического планирования должны реализовывать это требование, не ясно. Некогда существовавшая целевая программа по сокращению различий в социально-экономическом развитии субъектов Российской Федерации давно прекращена [7]. В действующем блоке государственных программ «Сбалансированное региональное развитие» конкретные механизмы реализации этой задачи не представлены. Задача сокращения названной дифференциации формально отмечена в Стратегии пространственного развития, однако четких оснований полагать, что предлагаемые ею новые институты и инструменты региональной политики государства на деле обеспечат такое сокращение, практически не имеется. Предлагаемые меры по закреплению требований безопасности в системе и ее целевых государственных программ, и проектов должны быть включены не только 
в Ф3 № 390 «О безопасности», но и в Ф3 № 172 «О стратегическом планировании...».

Конкретно значимым продвижением в этом направлении следует признать дополнения в ст. 28 Ф3 № 172 «Государственные программы Российской Федерации» указания относительно обязательного наличия в каждой государственной программе и национальном проекте показателей, характеризующих достигаемое за счет реализации программы или проекта приближение к требованиям национальной безопасности Российской Федерации. Пока же таких требований к структуре государственных и национальных программ нет, а сами требования, представленные в стратегиях безопасности, лишены достаточной конкретности. Складывается ситуация, когда реализация в практике стратегического планирования, программно-целевого управления и проектирования всех критериев национальной безопасности является и невозможным, и фактически необязательным.

Важным направлением совершенствования законодательства о безопасности является обеспечение условий эффективной «федерализации» этого направления государственной политики [8]. Формально в действующей версии ФЗ № 390 идея такой федерализации присутствует.

Так, ст. 12 данного закона говорит о том, что «органы государственной власти субъектов Российской Федерации и органы местного самоуправления в пределах своей компетенции обеспечивают исполнение законодательства Российской Федерации в области обеспечения безопасности». Однако вопрос о том, какова эта компетенция и как конкретно она должна реализовываться, остается открытым. Например, Федеральный закон «Об общих принципах организации законодательных (представительных) и исполнительных органов государственной власти субъектов Российской Федерации» ${ }^{13}$, который считается основным документом, конкретизирующим полномочия органов государственной власти субъектов Федерации, понятием «безопасность» оперирует лишь в отдельных вопросах, относящихся как к предметам ведения субъектов Федерации (безопасность дорожного движения; безопасность жизни и здоровья детей в период их пребывания в организациях отдыха), так и к предметам совместного ведения Федерации и ее субъектов (экологическая безопасность, безопасность гидротехнических объектов). Процедуру стратегирования экономической безопасности субъекта Федерации закон не предусматривает.

Примерно та же ситуация складывается и с Федеральным законом «Об общих принципах организации местного самоуправления в Российской Федерации» ${ }^{14}$. Здесь полномочия муниципалитетов по вопросам безопасности также касаются частных случаев (безопасности дорожного движения; пожарной безопасности; безопасности людей

13 Федеральный закон от 6 октября 1999 г. № 184-Ф3 «Об общих принципах организации законодательных (представительных) и исполнительных органов государственной власти субъектов Российской Федерации» // КонсультантПлюс. URL: http://www. consultant.ru/cons/cgi/online.cgi?req $=$ doc $\&$ base $=$ LAW $\& n=341979$

14 Федеральный закон от 6 октября 2003 г. № 131-Ф3 «Об общих принципах организации местного самоуправления в Российской Федерации» // КонсультантПлюс. URL: http://www.consultant.ru/document/cons_doc_LAW_44571/ 
на водных объектах и пр.), а вопрос о регулировании безопасного развития муниципального образования как целого не ставится.

В результате в действиях регионов и муниципалитетов в этом вопросе видна явная беспорядочность: ряд субъектов Федерации и экономически крупных муниципалитетов принимали или пытались разработать свои стратегии (концепции, программы) безопасности; в некоторых случаях проблематика безопасности отдельным «блоком» включалась в иные документы программно-стратегического характера, но чаще этот круг вопросов как особый объект регулирования вообще выпадал из поля зрения органов управления субфедерального уровня $[9 ; 10 ; 11]$. Внесение определенности в эту сферу федеративных отношений также является важной задачей обновления ФЗ № 390 «О безопасности».

Однако следует иметь в виду, что прямое включение субфедерального звена управления в систему мер по обеспечению национальной безопасности связано с целым рядом нерешенных вопросов. Подвергается сомнению даже само понятие «региональная безопасность» как феномен и объект управления, имеющий самостоятельное значение по отношению к национальной, в т.ч. экономической, безопасности на общегосударственном уровне. Кроме того, федеральный центр (если исключить угрозы и риски внешнего плана) как бы «самодостаточен» в обеспечении условий национальной безопасности. Другое дело - субъекты Федерации: многие параметры, традиционно относимые к понятию «региональная безопасность» в значительной мере, находятся в пределах полномочий федерального центра и на региональном уровне практически не регулируются. Могут ли в этих условиях субъекты Федерации и тем более муниципальные образования формировать свои стратегии (концепции и пр.) безопасности как реально значимые управленческие документы? Следует ли субъектам Федерации стремиться к формированию особых региональных стратегий безопасности или можно ограничиться соответствующим блоком вопросов в «базовых» стратегиях социально-экономического развития? Ответы на эти вопросы должны дать методические разработки, построенные на базе уже обновленного варианта Ф3 № 390 «О безопасности».

Резюмируя, следует сделать вывод, что в Ф3 № 390, помимо уже названного глоссария, необходимо законодательно закрепить положения о том, что, во-первых, стратегии безопасности принимаются и обнародуются с количественно выраженными пороговыми значениями и целевыми индикаторами (кроме сведений, относимых к государственной тайне).

Во-вторых, каждая новая стратегия по соответствующему профилю вопросов безопасности обязательно включает в себя раздел, количественно и качественно характеризующий степень реализации предшествующего аналогичного документа.

В-третьих, в каждом документе стратегического планирования (стратегиях социально-экономического развития страны и регионов, в отраслевых стратегиях, в государственных программах и национальных проектах, во всех видах прогнозов) необходимо в специальных разделах показывать, как планируемое или прогнозируемое развитие будет воздействовать на уровень экономической безопасности страны. 
Соответственно, в ФЗ № 172 о стратегическом планировании в ст. 28 «Государственные программы Российской Федерации» необходимо закрепить положение об обязательном включении во все программы раздела информации о том воздействии, которое каждая из программ и ее отдельные подпрограммы окажут на ключевые показатели экономической безопасности страны. Аналогичное требование может быть адресовано и государственным программам субъектов Федерации по мере разработки ими своих целевых индикаторов в сфере экономического и социального развития.

\section{Список литературы}

1. Кузнецова О.В. Стратегия пространственного развития Российской Федерации: иллюзия решений и реальность проблем // Пространственная экономика. 2019. Т. 15. № 4. С. 107-125.

2. Кардашова И.Б. Конституция Российской Федерации как основной источник обеспечения национальной безопасности // Вестник Университета прокуратуры Российской Федерации. 2018. № 5 (68). С. 51-57.

3. Бадылевич Р.В., Ульченко М.В., Кондратович Д.Л. Практика правового регулирования обеспечения экономической безопасности на федеральном и региональном уровнях // Фундаментальные исследования. 2019. № 7. С. 13-20.

4. Шох М.A. Региональная экономическая безопасность в системе уровней национальной безопасности // На страже экономики. 2018. № 1 (14). С. 51-56.

5. Городецкий A.E. Национальные стратегические задачи и экономическая безопасность // Труды Вольного экономического общества: сб. Т. 217. C. $137-158$.

6. Дамм И.А. Подходы к определению безопасности в законодательстве Российской Федерации // Юридическая наука и практика. 2019. Т. 15. № 1. С. $49-54$.

7. Бахтизин А.Р. Бухвальд Е.М., Кольчугина А.В. Выравнивание регионов России: иллюзии программы и реалии экономики // Вестник Института экономики РАН. 2016. № 1. С. 76-91.

8. Бухвальд E.M. Федерализм как основа национальной безопасности для России // Вестник Института Экономики РАН. 2018. № 1. С. 87-102.

9. Беспамятнов P.В. Стратегии обеспечения экономической безопасности регионов и крупных городов // Проблемы рыночной экономики. 2019. № 2. C. $55-63$.

10. Матвеева Е.Е. Гнездова Ю.В. Обеспечение уровня экономической безопасности региона // Бизнес. Образование. Право. Вестник Волгоградского института бизнеса. 2019. № 1 (46). С. 64-69.

11. Хорев А.И., Саликов Ю.А. Опыт формирования стратегии регионального развития с учетом приоритетных факторов экономической безопасности (на примере Воронежской области) // Экономическая безопасность России: проблемы и перспективы: материалы VI Международной научно-практической конференции. Н. Новгород: Нижегородский гос. технический ун-т им. Р.Е. Алексеева. 2018. С. 257-261. 


\section{NATIONAL SECURITY OF RUSSIA: OLD LAW AND NEW PROBLEMS}

In the near future, there will be a task to update such an important strategic planning document as the Strategy of national security of the Russian Federation. This task is due to the fact that the acting current Strategy of national was adopted in 2015, and in accordance with the Federal law "On Strategic planning in the Russian Federation", this Strategy must be updated at least once every 6 years. However, in the current situation, the elaboration of a new Strategy of national security is not just a renovation of an existing document. In essence, this is a systemic task, in which it is necessary to achieve the organic inclusion of this Strategy into a unified "vertical" of strategic planning documents. It is also necessary to strengthen the role of the Strategy as one of the key sources of goal-setting in the strategic planning practice and, of course, to fix in it the risks and threats to national security, including economic ones, which have developed during recent period. As a part of this work is expected significant updating the Federal law "On security", which is intended to fix the modern system of security strategies, their role in shaping strategic planning priorities, as well as in fixing the economic and legal foundations of federal relations in the country. Keywords: national security, economic security, risks and threats, strategic planning, goal setting, legal regulation

JEL: R12, R58

Дата поступления - 12.02.2020 г.

\section{БУХВАЛЬД Евгений Моисеевич}

доктор экономических наук, профессор; главный научный сотрудник; руководитель Центра федеративных отношений и регионального развития;

Федеральное государственное бюджетное учреждение науки Института экономики РАН / Нахимовский проспект, д. 32, г. Москва, 117218.

e-mail: buchvald@mail.ru

\section{BUKHVALD Evgeny M.}

Dr. Sc. (Econ.), Professor; Head of the Center for Federal Relations and Regional Development;

Federal State Budgetary Institution of Science Institute of Economics of the Russian Academy of Sciences / 32, Nakhimovsky Av., Moscow, 117218.

e-mail: buchvald@mail.ru

\section{Для цитирования:}

Бухвальд Е. Национальная безопасность России: старый закон и новые проблемы // Федерализм. 2020. № 1. С. 99-112. 